\title{
A study of job satisfaction and work engagement at the National Treasury of South Africa
}

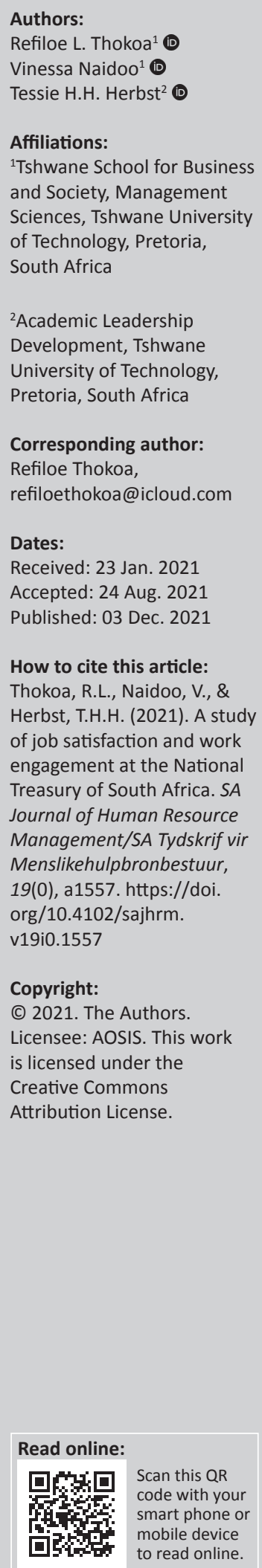

Orientation: There is overwhelming research on job satisfaction and work engagement as it relates to the private sector when compared with the public sector. Noting differences between the two sectors, the undeniable importance of the latter and that its employees are central to service delivery the dynamics of the concepts must be understood comprehensively. This study aims to add to this body of knowledge.

Research purpose: To determine the level of job satisfaction and work engagement at National Treasury, and whether job satisfaction is a significant predictor of work engagement.

Motivation for the study: South African Government's financial performance, which is largely the responsibility of National Treasury is unsatisfactory. As this responsibility is carried out by its employees, noting that job satisfaction and work engagement are some of the more recognised antecedents for employee performance, these need to be understood as the first step towards intervention.

Research approach/ design and method: A quantitative approach was followed wherein two questionnaires were administered via online census survey to all employees $(n=1189)$. Data collected were analysed using the mean and the frequency polygon. Multiple linear regression was conducted using Statistical Package for Social Sciences (SPSS).

Main findings: Somewhat low levels of job satisfaction and work engagement were observed. Multiple linear regression has confirmed that job satisfaction is a predictor of work engagement $\left(R^{2}=49.1 \%\right)$. It was also discovered that non-monetary aspects of the former such as communication and access to promotional opportunities are significant predictors while pay is not.

Practical / managerial implications: Job satisfaction, which relates to a focused state of work engagement, can also be harnessed through non-monetary aspects of the job.

Contribution/ value added: The study provided insight into the level of job satisfaction and engagement at National Treasury and reinforced the sentiment that satisfied employees tend to be vigorous, dedicated and absorbed.

Keywords: job satisfaction; work engagement; National Treasury; employee performance; audit outcomes.

\section{Introduction}

\section{Orientation}

This study was motivated by what seems to be weaknesses of National Treasury to appropriately manage two functions: the annual budget preparation function and the budget implementation monitoring function as illustrated through negative audit outcomes expressed by the Auditor General of South Africa. These audit outcomes are based on an objective assessment of a department's compliance with financial legislation and the extent to which appropriated budgets have been implemented in line with departmental performance plans for service delivery (Auditor General of South Africa, n.d.). The audit outcomes of 2016-2017 indicated that only 30\% of the total population audited at the national government level received clean audits (Auditor General of South Africa, 2017). These aforementioned functions, mandated through the Public Finance Management Act (Republic of South Africa, 1999), are aimed at ensuring government departments achieve good audit outcomes as support would be given to ensure that realistic budgets are crafted and adequately implemented in line with applicable financial legislation and that allocated resources enable the given departments to provide good service delivery (Department of National Treasury, 2015). Parliament of South Africa (2016) and Department of National Treasury (2011) provide further detail on the functions as follows: 
- Budget preparation function: This is a lengthy function with various sub-processes, such as the assessment of proposed budget reallocations and budget bids for new priorities, wherein budget and resource allocation decisions for all national government departments are made by National Treasury before the annual national budget is tabled in Parliament. Employees would need to apply their budget management knowledge and expertise and extensively interact with national government departments to support them in crafting realistic and reliable budgets.

- Budget implementation monitoring function: This involves the continuous monitoring and analysis of public expenditure and assessing the impact thereof on service delivery. Employees would need to apply their knowledge of sector policy goals and provide close support to departments to ensure that allocated budgets are expeditiously implemented, in line with relevant legislation, to achieve the given sector goals.

The Department of National Treasury (2019) suggested that the National Treasury is a service organisation as its employees would need to interact with, and in a sense serve, government departments as they carry out the aforesaid functions. These functions form part of its ultimate organisational service promise to ensure prudent management of public finances. Given the sentiment of Skaalsvik (2017) that in the case of service organisations, employees make up part of an organisation's actual service as they carry out the various activities involved in performing a given service promise, greater focus needs to be placed on ways to improve employee performance. Job satisfaction and work engagement are suggested as appropriate ways to harness employee performance (Alzyoud, 2018). Garg, Dar and Mishra (2017), Ludviga and Kalvina (2016) and Yalabik, Rayton and Rapti (2016) suggested that a positive feeling regarding one's job increases the likelihood of a vigorous, dedicated and absorbed manner of interaction with their work. This is also the basis for the hypothesis statement in the study.

Earlier thinking on employee performance was largely centred on the belief that money was the most significant motivator. This is mainly because of work, such as the theory of scientific management, by Taylor (1919), which treated humans as purely money driven beings. This implied that employee performance would only be a function of the perceived adequacy of remuneration levels. It was only during the mid1900s that this thinking evolved to realise the importance of positive psychology (Gable \& Haidt, 2005), with its popularity later expedited by the seminal work of authors such as Seligman (1994) and Seligman and Csikszentmihalyi (2000), leading to greater consideration that 'experiences of positive emotion are beneficial for individuals because they serve to broaden perceptive, focus and attention' (Lambert, PashaZaidi, Passmore, \& York Al Karam, 2015, p. 3). This also led to increased appreciation of the influence of other factors such as job satisfaction and work engagement on employee performance (Mills, Fleck, \& Kozikowski, 2013). Khan, Khan,
Nawaz and Qureshi (2013) and Lopez and Gallagher (2009) mentioned that positive psychology is based on the belief that human strengths and qualities can be boosted to ensure that individuals function optimally, creatively and effectively in the workplace. This type of psychology particularly acknowledges the dynamism of human behaviour and would be useful to managers because employee performance remains a challenge (Orin, 2010). The application of punitive measures for poor employee performance is also discouraged with authors such as Mogab, Kishan and Vacaflores (2013) referring to domestic labour legislation as overly protective. Employers, therefore, need to seek amicable ways to encourage good performance (Bhorat, Naidoo, \& Yu, 2014).

A positive correlation between job satisfaction and performance was confirmed by studies such as those of Bakotić (2016), Khan, Nawaz, Aleem and Hamed (2012), and Latif, Ahmad, Qasim, Mushtaq, Ferdoos and Naeem (2013) amongst others. A similar correlation was determined for work engagement and performance in studies by Kim, Kolb and Kim (2012), Rana, Pant and Chopra (2019), and Yongxing, Hongfei, Baoguo and Lei (2017). Bellani, Ramadhani and Tamar (2018), Garg et al. (2017) and Tepayakul and Rinthaisong (2018) also found that job satisfaction is a predictor of work engagement, which then impacts performance. As these concepts are amicable ways to promote performance as suggested by Abu-Shamaa, Al-Rabayah and Khasawneh (2015), application thereof would be useful particularly in the South African labour market.

Bakker (2017) and Inuwa (2016) considered job satisfaction and work engagement as valuable topics in modern management, particularly in light of the seeming consensus towards a positive psychological approach for managing performance (Lambert et al., 2015), given their proven link to employee performance (Alzyoud, 2018). Inuwa (2016), and Ziapour and Kianipour (2015) stated that much of the research relating thereto has largely focused on the private sector. This is probably not surprising because at the core of the very survival of business is market competitiveness, which can be achieved through superior employee performance (Zuñiga-Collazos, Castillo-Palacio, \& PadillaDelgado, 2019). Macleod and Clarke (2009), however, argued that much of the work of the public sector involves complex policy issues, with organisational performance in the sector being a direct function of whether public services are appropriately delivered to citizens. Thus, organisational performance that usually results from employee performance (Skaalsvik, 2017) is arguably just as important as it would be in the private sector. This warrants research relating to the concepts under review in this study to be progressively increased for the public sector to match that available for the private sector. It is easy to imagine how a favourable feeling towards one's job, which is one of the definitions for job satisfaction (Aziri, 2011), would probably make it easier for one to be more engaged in their work in the private sector environment where undesired consequences for poor performance are usually severe and accountability is stringently applied (Khan \& Khandaker, 2016). In a sector 
where this is not the case, the choice to not be engaged in one's work despite possessing this feeling is perhaps easier. Given this difference between the sectors, it should not be readily assumed that job satisfaction would predict work engagement as has been proven over and over again in the private sector. This needs to be tested and established in formal research, using the case of a vast number of different government institutions, at least to level of available literature for the private sector. Doing this would also address the sentiment that both concepts are generally under-researched in the public sector. This study aims to contribute in both respects.

\section{Research purpose and objectives}

The study, relying on the notion that job satisfaction and work engagement are appropriate and amicable ways to improve employee performance, focused on these concepts at National Treasury. Specifically, the objectives of this study are as follows:

- To determine the level of job satisfaction and work engagement at National Treasury: A case has been made that National Treasury is a service providing organisation, relying heavily on its employees to carry out the functions articulated earlier. These functions are meant to ensure that government achieves good audit outcomes, the negative audit outcomes seen thus implies that National Treasury's performance is not adequate. As these functions are performed by its employees, employee performance can be said to be inadequate and requires intervention. Understanding the level of job satisfaction and work engagement would be a good starting point for crafting an intervention strategy that considers the context of positive psychology.

- To determine whether job satisfaction is a significant predictor of work engagement: while the link between job satisfaction and work engagement has been established in literature much of this was based on the private sector context (Bellani et al., 2018; Garg et al., 2017; Tepayakul \& Rinthaisong, 2018). Taking this fact into account and that the public sector is driven by political forces wherein competitiveness is not much important (Khan \& Khandaker, 2016), further dedicated public sector research on this link by different types of government institutions is important. In addition, a quick google search for studies that aim to determine this link in this manner for national government departments, such as National Treasury, in South Africa yielded no useful results.

\section{Literature review}

Since the advent of positive psychology, there has been a significant growth in its appreciation, both in academia and the industry as a means to manage performance (Orin, 2010). Gable and Haidt (2005, p. 103) highlighted the difference between traditional and positive psychology, by stating that the former is, in essence, about 'learning how to bring people up from negative eight to zero' while the latter is more concerned about 'understanding how people rise from zero to positive eight'. Furthermore, traditional psychology is more curative because it seeks to resolve already existing problems and synonymises well-being with the absence of problems or illness in the present. Positive psychology, on the other hand, follows a preventative approach to care by suggesting that creating positive emotions and building on human strengths would minimise the likelihood of the occurrence of problems in the first place. It also postulates that well-being reduces vulnerability for future problems (Lambert et al., 2015).

Job satisfaction and work engagement, as defined in this study, seem more appropriately placed within the realm of positive psychology. Bellani et al. (2018) mentioned that operationalising these concepts essentially entails getting employees to have favourable feelings about the workplace in general, thereby increasing the probability of their appropriate involvement in the various work tasks. Consequently, future vulnerability to workplace-related problems is limited, thereby achieving and sustaining good employee performance. This idea also aligns with the hypothesis statement of this study. South African labour legislation seems to lean more towards a positive psychology approach by introducing the term of corrective discipline. The Labour Relations Act (Republic of South Africa, 1995) refers to corrective discipline as the process through which an employer should attempt to correct employee behaviour through a graduated system of discipline, which would start with counselling and informal advice.

\section{Job satisfaction}

Job satisfaction is said to be potentially the most researched concept in organisational behaviour with more than 10000 studies published, but very few of these focusing on the public sector (Inuwa, 2016). It has been proven to be a significant predictor of performance, particularly through the demonstrated ability to get employees to be appropriately focused and involved in the workplace (Wright, 2006). Wright further stated that appreciation of the concept began as early as the 1900s when authors such as Gilbreth (1911) observed that employees who believed that their earnings were commensurate with the effort exerted in the workplace, were happier and more enthusiastic to take on work tasks compared with those who did not. This observation suggested the presence of contentment, which seemed to be a notable contributor to employee performance. It was later observed that any employee sentiments and feelings towards work would determine contentment (Wright, 2006). This suggested that there may be a vast number of factors that influence job satisfaction, making it a very complex concept to understand (Arifin, Nirwanto, \& Manan, 2019). As such, management teams often find it challenging to ensure that employees are consistently satisfied. Aziri (2011) indicated that this complexity is evident in the fact that there are various definitions of job satisfaction available in literature and mentioned the following as examples: 
- A positive feeling that results from how psychological, physical and environmental factors, which have to do with the job and the workplace, relate with each other.

- It is a reflection of the extent to which an employee is competent in the various roles of the particular job.

- It represents a worker's sense of achievement in the workplace.

Field (2008) succeeded in simplifying the job satisfaction concept through a basic job satisfaction model. This model suggested that job satisfaction impacts employee fulfilment, commitment and engagement. It also provided common factors such as pay and work conditions, which increase the likelihood of an employee to either be satisfied or dissatisfied. Job satisfaction and dissatisfaction are seen as opposites, the more favourable the common factors the more likely an employee is to experience job satisfaction (Popović, Maletić, \& Paunović, 2015). Spector (1985) suggested that the concept is a sum of nine favourable factors, namely pay, promotion, supervision, benefits, contingent rewards, operating procedures, co-workers, nature of work and communication. Rabbanee, Yasmin and Mamun (2016), Bellani et al. (2018) and Spector (1985) explained these as follows:

- Pay: Refers to the wages that form part of an employee's compensation package for a given job. The perceived appropriateness of the level of wages to workplace demands is as important as perceptions of fairness when compared with those earned by other employees within the organisation and industry at large.

- Promotion: The importance of access to promotional opportunities within the organisation for employees stems from the prospect that these would also provide for personal growth, improved social status and increased responsibility.

- Supervision: This factor is concerned with how immediate supervisors manage their subordinates. A good supervisor can create an environment where employees feel safe and confident to fully express themselves. This can be achieved by valuing the opinions and views of employees and coming across as friendly and knowledgeable.

- Benefits: These refer to employee fringe benefits, often seen as employers' way for providing personal protection, which are made over and above pay and includes medical aid cover, tuition reimbursement and retirement savings.

- Contingent rewards: These rewards may be of a financial or non-financial nature made by employers with the specific intention to express appreciation for outstanding performance.

- Operating procedures: It refers to the collection of various rules, procedures and processes applicable within the organisation. An example would include the process for which project approvals would need to undergo before implementation. Too much red tape has the potential to discourage employees.

- Co-workers: Given the rather protracted periods spent at work, social interaction is necessary for most employees. Having friendly co-workers who can provide advice and support in the achievement of individual performance goals is preferred.

- Nature of work: Work is enjoyable only if its employees are satisfied with its various aspects. These include basic daily tasks and other periodic or special tasks that may be required from time to time.

- Communication: The extent to which employees are informed about the organisation and things that impact the organisation is important, particularly those who pertain to their obligations to the organisation and work demands. Communication is critical at all levels and should not be limited to the immediate supervisor and subordinate level.

This study relies upon the operational definition of concept, which is provided as the sum of the nine factors of Spector (1985).

\section{Work engagement}

Schaufeli (2012) mentioned that the concept of work engagement emerged in the 1990s and has since become very popular in academia and in business. It, along with job satisfaction, grew in popularity because of the general shift in organisational behaviour towards a positive psychological approach. Its importance was further highlighted by the results of an international survey conducted in the late 1990s amongst chief executive officers. The survey found the absence of universally acceptable practices to enhance employee engagement to be in the top five challenges proposed in the survey (Schaufeli, 2013). Bakker (2017) stated that there are more than 100 studies validating a strong positive relationship between work engagement and organisational performance. Following the review of more than 200 publications, Schaufeli (2013) found common descriptions of work engagement based on four main approaches, namely the needs-satisfying approach rests on the desire of an employee to positively express himself or herself when performing their roles in the workplace. The burnoutantithesis approach consists of two main schools of thought. On the one hand, burnout is probably the most obvious to recognise and features to some extent in current literature. Work engagement is thus, proposed as a way of avoiding the undesirable state of burnout. On the other hand, work engagement is not seen as quite the opposite of burnout but rather separate and is characterised by vigour, dedication and adsorption. The satisfaction-engagement approach emerged in the 1990s and the early 2000s and synonymises the concept of involvement, which was believed to largely make up engagement and satisfaction. In other words, a satisfied employee will be involved in the workplace. Lastly, the multidimensional approach was established in the mid-2000s when various authors started using combinations of the needssatisfying, burnout-antithesis and satisfaction approaches. As discussed earlier, Bellani et al. (2018), Garg et al. (2017), and Tepayakul and Rinthaisong (2018) suggested that satisfied employees are more likely to display higher work engagement levels. This implies a more focused state of interaction with the workplace, leading to improved 
performance. In support, Viswesvaran, Schmidt and Ones (2005) stated that engaged employees are less prone to make mistakes and are generally more efficient. Schaufeli and Bakker (2004) introduced another perspective that focused on the direction of causality between job satisfaction and work engagement. It is suggested that work engagement is the initial source of job satisfaction in a continuous cycle wherein one results in the other.

This study relied on the following definition of work engagement:

A positive, fulfilling, work-related state of mind that is characterized by vigour, dedication and absorption. Rather than a momentary and specific state, engagement refers to a more persistent and pervasive affective-cognitive state that is not focused on any particular object, event, individual or behavior [sic]. (Schaufeli \& Bakker, 2004, p. 15)

Another definition referred to the concept as two dimensional, namely attention and absorption. Saks (2006, p. 601) referred to the concept as the 'psychological presence of an employee'.

\section{Articulating the hypothesis statement: Employees' level of job satisfaction has a significant positive relationship with work engagement}

According to Garg et al. (2017) various studies found job satisfaction to be closely related to work engagement. Ludviga and Kalvina (2016) supported this by highlighting the wide following in industry and academia on the idea that job satisfaction is an ascendant of work engagement. Furthermore, it is reasonable to expect that an employee who has a positive feeling that resulted from favourable interaction between psychological, physical and environmental factors of the job and the workplace (job satisfaction) (Aziri, 2011) would be more prone to vigour, dedication and adsorption in the workplace (work engagement) (Schaufeli \& Bakker, 2004). Yalabik et al. (2016) supported this by referring to the satiation-activation concept. Satiation relates to satisfaction that results from the favourable outcome of the emotional evaluation of the job. Activation refers to a positive state of directed behaviour and thus relates to work engagement. The idea is that satiation would inform activation. These findings from literature inform the hypothesis statement of the study as depicted in Figure 1.

An employee would therefore, generally expect that being focused, dedicated and energetic would increase his or her performance, which in turn should bring about greater rewards, recognition and growth within the organisation. Consequently, the likelihood of the said employee acquiring

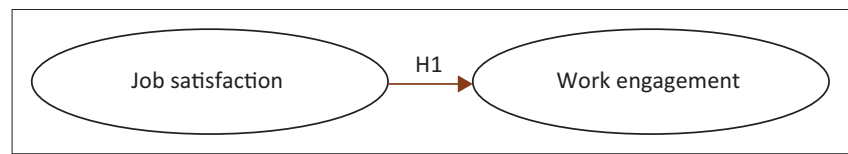

FIGURE 1: Graphic representation of the hypothesis statement for the study. positive feelings about the organisation increases and it leads to job satisfaction. This satisfaction would then fuel work engagement and so on.

The given discussions clearly affirm that job satisfaction positively influences the manner in which employees interact with their work. Depending on the situation and their individual preferences, employees are either displeased with their jobs or draw pleasure from it. Various studies in different sectors have provided evidence that performance is linked with job satisfaction (Bakotić, 2016; Khan et al., 2012; Latif et al., 2013) and work engagement (Kim et al., 2012; Rana et al., 2019; Yongxing et al., 2017). Thus, the claim that the absence of job satisfaction is harmful to an organisation can be accepted. Despite several studies on job satisfaction and work engagement being available in literature, little has been done in the context of the public sector and the National Treasury, which is a key government department. Thus, this study would address this gap.

\section{Research design \\ Research approach}

This study is descriptive in nature as it aims to provide an accurate description of the study constructs and uses this information to determine the relationship between the two (Allwood, 2012). The study also follows a quantitative research design as it relies on numerical data for measurement and testing (Saunders, Lewis, \& Thornhill, 2016).

\section{Research method}

The study employed a cross-sectional design, which is one wherein phenomena is studied at a particular time (Saunders et al., 2016). Questionnaires were administered to all National Treasury employees to obtain perceptions of job satisfaction and engagement. The envisaged relationship between the two study constructs was based on a review of literature and data collected were used to measure these constructs and test the hypothesis statement for the study.

\section{Research participants and sample}

The research participants were the employees of the National Treasury. An online census survey, wherein the questionnaires were sent to the entire population $(n=1189)$, was followed to ensure that the voices of all employees who wished to participate were included, to increase the likelihood of a good response rate and to ensure improved representation across various demographical factors. A response rate of 42.1\%, 501 of 1189, was achieved. Demographic information was collected on gender, job grade and level of education to better understand the respondents (see Table 1).

Closer inspection of Table 1 reveals that most of the respondents were male respondents at $53.9 \%$ (270). A total of 25 respondents equalling $5.0 \%$ opted not to disclose their gender. For job grade, majority of the respondents were senior managers at 39.7\% (199), followed by junior managers 
TABLE 1: Demographic information of respondents.

\begin{tabular}{|c|c|c|c|}
\hline Demographic & Demographic detail & $n$ & $\%$ \\
\hline \multicolumn{4}{|l|}{ Gender } \\
\hline & Male & 270 & 53.9 \\
\hline & Female & 206 & 41.1 \\
\hline & Other & 25 & 5 \\
\hline & Total & 501 & 100 \\
\hline \multicolumn{4}{|l|}{ Job grade } \\
\hline & Senior management (SL13) & 199 & 39.7 \\
\hline & Junior management (SL9-10) & 103 & 20.6 \\
\hline & Middle management (SL11-12) & 101 & 20.2 \\
\hline & Top management (14-16) & 58 & 11.6 \\
\hline & Non-management (SL1-8) & 39 & 7.8 \\
\hline & Unknown management class (>SL16) & 1 & 0.01 \\
\hline & Total & 501 & 100 \\
\hline \multicolumn{4}{|c|}{ Level of education } \\
\hline & Doctoral degree & 11 & 2.2 \\
\hline & Master's degree & 274 & 54.7 \\
\hline & Bachelor Honours & 131 & 26.1 \\
\hline & Bachelor's degree & 68 & 13.6 \\
\hline & Diploma & 11 & 2.2 \\
\hline & Higher certificate & 4 & 0.8 \\
\hline & National senior certificate & 2 & 0.4 \\
\hline & Total & 501 & 100 \\
\hline
\end{tabular}

with $20.6 \%$ (103) and only 1 respondent indicated a job grade above Level 16. The level of participation increases with the qualification level from national certificate to master's degree. Only $0.4 \%$ (2) of the respondents held national certificates, $0.8 \%$ (4) higher certificates and 2.2\% (11) diplomas. Those with bachelor's degrees were $13.6 \%$ (68) and $26.1 \%$ (131) held an honours degree. Most of the respondents had a master's degree at $54.7 \%$ (274).

\section{Measuring instruments}

This study used the English version of the Utrecht Work Engagement Scale (UWES) by Schaufeli and Bakker (2004) and the original version Job Satisfaction Survey (JSS) by Spector (1985) because these are amongst the most extensively used and recognised in the field (Batura, Skordis-Worrall, Thapa, Basnyat, \& Morrison, 2016; Wickramasinghe, Dissanayake, \& Abeywardena, 2018). Each have been designed to measure the constructs that are believed to make up work engagement and job satisfaction, based on the definitions discussed in the literature review section, as follows (Schaufeli \& Bakker, 2004; Spector, 1985):

- The UWES has a total of 17 items grouped within three subscales: Firstly, the vigour subscale, which consists of 6 items. Secondly, the dedication subscale, which consists of 5 items and lastly the adsorption subscale, which consists of 6 items. Psychometric evaluation of the instrument was conducted across different counties including South Africa confirming its factorial validity, reliability, stability upon test retest and cross-national applicability.

- The JSS has a total of 36 items within nine subscales: All subscales consist of 4 items and are meant to measure pay, promotion, supervision, benefits, contingent rewards, operating procedures, co-workers, nature of work and communication. A psychometric evaluation of the instrument was conducted across 19 organisations in the public, service, non-profit sectors and municipal public works. In all cases, the proposed nine factor solution was confirmed, appropriateness of its use across various service organisation types, stability upon test resting and reliability were also illustrated.

Both developers of the surveys established validity by using factor analysis. Both instruments have also been used in various other studies (Jacobs, Renard, \& Snelgar, [2014]; Musenze \& Mayende [2020]; Steyn, [2016]) for UWES and Ani \& Mirela [2016]; Maleka, Paul-Dachapalli, Ragadu, Schultz, \& Van Hoek, [2020]; Syeda, Nighat, \& Syeda, [2017] for JSS) and their validities illustrated, with high interrelations between the proposed factors usually resulting (Kulikoski, 2019). This study relied on the face validity of the instruments, which was carried through the pre-testing process wherein three practicing human resource experts in a government department were requested to review the instruments as recommended by Taherdoost (2016), and all agreed that it seemed to measure what it should measure and thus constitute face validity (Saunders et al., 2016). A professor of human resources management also reviewed the instrument and has also provided this confirmation.

Both authors recommended the use of the Likert-scale approach to obtain data and suggest the use of mean scores to interpret results. The closer the mean score to the highest possible positive response option, the greater the presence of the construct measured by the respective scale. The opposite would be true for those close to the lowest possible response option. This study opted for a 7-point Likert scale, starting from 'strongly disagree' to 'strongly agree', as lower scales have been criticised for providing options that are radically different from each other (Joshi, Kale, Chandel, \& Pal, 2015). Response options were assigned values from 1 to 7 , from lowest to highest options with the highest being preferred. The basis of this ranked superiority stems from the context of the questionnaire items in the field of organisational behaviour, for instance; a ' 7 ', or strongly agree, for 'at work, I feel bursting with energy' which is one of the items of the UWES.

Saunders et al. (2016) and Manikandan (2011) further suggested the use of graphic representations of frequency distributions, such as frequency polygons, as these make it easy to summarise total data gathered while also showing the skewness of data. Skewness refers to the extent to which a distribution curve deviates from a normal curve wherein the curve would peak on the centre value, which is 4 in this study. A negatively skewed polygon, indicating more positive scores, would peak on the positive side, which would be on the righthand side of the centre value (Saunders et al., 2016).

For reliability, Cronbach's alphas of 0.865 and 0.861 were obtained, respectively, for the pilot study using 37 respondents. For the main study, as shown in Tables 2 and 3, overall values of 0.975 and 0.952 were obtained, which are above the recommendation of 0.7 . The average inter-item correlation was also used with values ranging between 0.20 
and 0.4 indicative of reliability in cases where Cronbach's alpha was below 0.7 as recommended by Pallant (2007).

\section{Research procedure and ethical considerations}

The data were collected using an online survey, which was sent to all National Treasury $(n=1189)$ employees. Given the sensitivity of the subject and to ensure that respondents were as truthful as possible, the study was anonymous and respondents were informed of this anonymity in a signed letter by the researcher that was included in the email, which contained the link to the online survey. Participation was voluntary and respondents were also free to withdraw during the survey. Written permission to obtain data from the employees and to publish the National Treasury name was obtained from the Director General. The ethics committee of a University in Gauteng granted ethical clearance for the study.

\section{Statistical analysis}

Descriptive and inferential statistical data analysis methods were used via the Statistical Package for Social Sciences (SPSS) version 25. Frequency tables (Tables 2 and 3) show the mean and standard deviation used for the descriptive analysis. Multiple linear regression was used to test for the direction and strength of the relationship between job satisfaction, including its nine components as provided by Spector (1985) and work engagement. Responses received for all negatively worded items were reversed for the ease of analysis.

\section{Results \\ Level of job satisfaction and work engagement}

The total mean value of 5.151 for the responses relating to job satisfaction (Table 2) and that of 5.789 for the responses relating to work engagement (Table 3 ) are both above the

TABLE 2: Frequency distribution for job satisfaction survey.

\begin{tabular}{lccc}
\hline Scales & Cronbach's alpha & Mean & SD \\
\hline Pay & 0.818 & 5.273 & 1.381 \\
Promotion & 0.852 & 5.519 & 1.733 \\
Supervision & 0.750 & 5.495 & 1.271 \\
Benefits & 0.800 & 5.288 & 1.370 \\
Contingent rewards & $0.538^{*}$ & 4.343 & 1.386 \\
Operating procedures & 0.729 & 4.398 & 1.434 \\
Co-workers & 0.751 & 5.353 & 1.155 \\
Nature of work total & 0.844 & 5.971 & 1.146 \\
Communication total & 0.858 & 4.715 & 1.644 \\
\hline Total scales (Job satisfaction) & $\mathbf{0 . 9 5 2}$ & $\mathbf{5 . 1 5 1}$ & $\mathbf{1 . 3 9 1}$ \\
\hline
\end{tabular}

*Average inter-item correlation of 0.225 was computed and used in the place of Cronbach's alpha for reliability, with values ranging between 0.20 and 0.40 deemed appropriate as recommended by Pallant (2007), for contingent rewards.

TABLE 3: Frequency distribution for Utrecht Work Engagement Scale.

\begin{tabular}{lccc}
\hline Scales & Cronbach's alpha & Mean & SD \\
\hline Vigour & 0.940 & 5.841 & 1.135 \\
Dedication & 0.923 & 5.911 & 1.152 \\
Absorption & 0.916 & 5.617 & 1.165 \\
\hline $\begin{array}{l}\text { Total scales (Work } \\
\text { engagement) }\end{array}$ & $\mathbf{0 . 9 7 5}$ & $\mathbf{5 . 7 8 9}$ & $\mathbf{1 . 1 5 0}$ \\
\hline
\end{tabular}

centre value of 4 indicating appropriate levels. However, there is still room for improvement for both as the former is closer to the third best-preferred option, which is 5 on the Likert scale. The latter is closer to the second-best preferred option, which is 6 on the Likert scale.

To provide a more detailed summary, the total number of responses received in each response category was used to construct the frequency polygon for job satisfaction and work engagement (Figure 2). The centre value of 4 is illustrated with a red vertical line in the frequency polygon. The frequency polygon peaks on the right-hand of the centre, which indicates negatively skewed responses and implies more positive results. This supports the interpretation made using the mean.

\section{Results from hypothesis testing}

Multiple linear regression analysis was conducted using SPSS and interpreted using the guidance of Dhakal (2018). All assumptions of regression were met, with $n=326$ used after outliers were removed using Mahalanobis distance. Its maximum value started at 138.36 but was soon reduced to 27.76 after 10 iterations of removing outliers by SPSS. This is below the suggested critical value of 27.88 determined by using a chi-square table with 9 as our degrees of freedom as 9 predictors were loaded in the regression model (Pallant, 2007). The analysis of variance (ANOVA) table is the first output of the multiple linear regression model and indicates whether the model has statistical significance. A $p$-value below the level of significance of 0.05 , used in this study, indicates that the predictors predict the dependent variable in a statistically significant manner. The coefficient of determination $\left(R^{2}\right)$ provides for the proportion of the variance explained by the predictors. The $R^{2}$ value of 0.491 , indicates that $49.1 \%$ of the variance in work engagement is explained by job satisfaction and is close to the threshold of what would be considered a strong explanation of variance, which is usually 0.5 (Gogtay \& Thatte, 2017). The model also provides $p$-values for each predictor to help identify

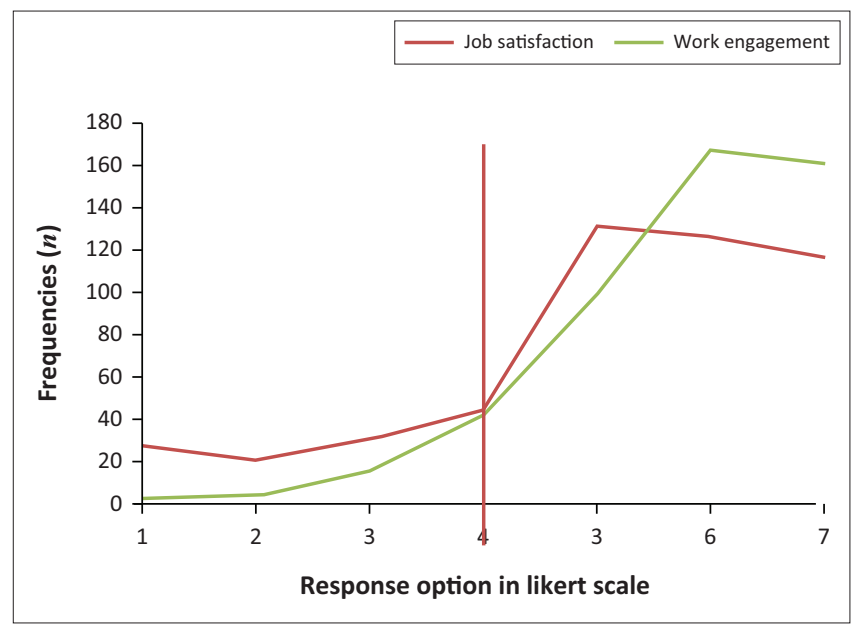

FIGURE 2: Frequency polygon for job satisfaction and work engagement at National Treasury. 
TABLE 4: Validation of hypothesis statement.

\begin{tabular}{|c|c|c|c|c|c|}
\hline $\begin{array}{l}\text { Dependent } \\
\text { variable }\end{array}$ & Predictors & $\begin{array}{l}\text { Unstandardised } \\
\text { coefficient } \\
(B)\end{array}$ & $\begin{array}{c}p \text {-value of } \\
\text { predictor }\end{array}$ & $\begin{array}{c}p \text {-value } \\
\text { of } \\
\text { model }\end{array}$ & $R^{2}$ \\
\hline \multirow{9}{*}{$\begin{array}{l}\text { Work } \\
\text { engagement }\end{array}$} & 1. Pay & 1.437 & 0.678 & $<0.000$ & 0.491 \\
\hline & 2. Promotion & 0.058 & $<0.000$ & & \\
\hline & 3. Supervision & 0.452 & 0.071 & & \\
\hline & 4. Benefits & 0.438 & $<0.000$ & & \\
\hline & 5. Contingent rewards & -0.790 & 0.749 & & \\
\hline & 6. Operating procedures & -0.060 & $<0.000$ & & \\
\hline & 7. Co-workers & -0.717 & 0.803 & & \\
\hline & 8. Nature of work & -0.052 & -0.001 & & \\
\hline & 9. Communication & 0.595 & $<0.000$ & & \\
\hline
\end{tabular}

those with noteworthy impact using the beta coefficient $(B)$. $B$ indicates the exact value change in the dependent value that would result when the particular predictor increases or decreases by one unit (Dhakal, 2018; Pallant, 2007). Accordingly, the following predictors are determined to predict work engagement in a statistically significant manner (Table 4):

- With one unit increase in promotion, work engagement increases by 0.058 .

- With one unit increase in benefits, work engagement increases by 0.438 .

- With one unit increase operating procedures, work engagement decreases by 0.060 .

- With one unit increase in nature of work, work engagement decreases by 0.052 .

- With one unit increase in communication, work engagement increases by 0.595 .

\section{Discussion Outline of results}

It is important to observe the idea that the poor government audit outcomes relate to National Treasury's inability to adequately perform the annual budget preparation and the budget implementation monitoring functions, through its employees as suggested by Department of National Treasury (2019). If the premise that job satisfaction and work engagement are amongst notable antecedents for good employee performance, the results of this study would seem to support the idea. While noting that there is a vast number of antecedents to employee performance, further research has suggested that job satisfaction $(m=5.151)$ and work engagement $(m=5.789)$ are amongst the more significant predictors (Schaufeli \& Bakker, 2004; Zuñiga-Collazos et al., 2019) and have been found to need improvement in the case of National Treasury.

Results from the regression analysis corroborate the established view, largely in the private sector, that job satisfaction notably facilitates work engagement $\left(R^{2}=0.491, p<0.000\right)$ even in the case of the public sector, despite the inherent differences between the two. The results also seem to support the notions of Lambert et al. (2015) and Gable and Haidt (2005) that employees are not entirely driven by money as pay was found not to be a notable predictor of work engagement ( $p=0.678$ ).
Furthermore, However, knowledge of the prospect for personal growth and personal protection provided by the employer, which underpins positive emotions and promotes feelings of being valued by the employer, can be achieved through improved access to opportunities for promotion $(B=$ $0.058, p<0.000)$ and good fringe benefits $(B=0.438, p<0.000)$, respectively, as suggested by Uysal, Aydemir and Genc (2017). Both of which were found to be significant predictors of work engagement as indicated. This also aligns with the statement of Lambert et al. (2015) that experiences of positive emotions are beneficial as they broaden perceptive and facilitate focus and attention, which are some components of work engagement (Saks, 2006). It is not surprising that communication is found to be the strongest predictor $(B=$ $0.595, p<0.000)$. Schaufeli and Taris (2014) mentioned that the appropriate alignment between job demands, which refers to physical and mental effort required in a job and job resources, which refers to aspects of the job that facilitate the performance of work tasks, prevents burnout, which is seen as the opposite of work engagement. Bucăţa and Rizescu (2017) mentioned that without communication not only will employees not know what is expected from them but will also not know which job resources are at their disposal and how to access these. Thus, the inadequate use of job resources may thus ensue increasing the likelihood of burnout. The direction of the relationship between work engagement and nature of work $(B=-0.052, p=0.001)$ and operating procedures $(B=-0.060$, $p<0.000)$ as predictors were found to be negative. Perhaps this links with the widespread belief that the public sector jobs are typically not challenging and that the sector cannot provide job resources to the level of the private sector (Do Monte, 2017; Zuñiga-Collazos et al., 2019), thus entrants already come into the sector with low expectations relating to the nature of work and operating procedures.

\section{Practical implications}

The study suggests that employees can be kept vigorous, dedicated and absorbed in their work, which all relate to improved employee performance, by igniting positive feelings about the job which is job satisfaction and happens to be amongst some of the more recognised antecedents for work engagement (Aziri, 2011; Schaufeli \& Bakker, 2004). As the South African government is facing challenging financial times, which implies that salaries cannot be as easily increased as before (Department of National Treasury, 2020), other non-monetary aspects of job satisfaction need to be carefully considered to promote superior employee performance. The findings confirmed that supervision, assuming a level of significance of 0.10 , and communication can be used to improve on work engagement. Thus, managers and team leaders at the treasury need to provide appropriate and supportive supervision. For human resource managers communication, at all levels, needs to be prioritised as it was found to be the strongest predictor for work engagement. A dedicated two-way communication system, where employees and 
managers and employees with other employees can freely and without prejudice express themselves may be useful.

\section{Limitations and recommendations for future research}

The researcher (RLT) is an employee of the National Treasury and colleagues, perhaps not entirely convinced of anonymity, may have given slightly more positive responses. This may have led to the overestimation of both the constructs measured. The research design of the study wherein structured data collection instruments were used may have effectively silenced other views on the topic, which the researchers may not have necessarily conceptualised. This study is also rather employee focused and does not take into account the views of the Minister and the Director General of the National Treasury who collectively own all organisational policies including those relating to human resources (Department of National Treasury, 2019).

It has been highlighted that job satisfaction and work engagement are well researched in the private sector and not in the public sector (Inuwa, 2016; Ziapour \& Kianipour, 2015). Given the absence of market competitiveness, which is shown to usually drive a culture of satisfaction, engagement and performance from top levels to the very bottom levels (Zuñiga-Collazos et al., 2019) research directed thereto is important for the public sector. This is also supported by the sentiment of Macleod and Clarke (2009) that the work of this sector impacts government service delivery.

\section{Conclusion}

This study set out to determine the level of job satisfaction and work engagement at the National Treasury, and whether the former is a significant predictor of the latter as the first step towards supporting the owners of its policies to develop an intervention plan. The poor audit outcomes observed for national government suggested that National Treasury is not performing the budget preparation and budget implementation monitoring functions adequately. As these functions are carried out by employees because National Treasury is a service organisation, it is further suggested that employee performance may be inadequate. Given that job satisfaction and work engagement are amongst the more recognised ways to improve employee performance, understanding its dynamics may be useful.

The need for an intervention plan is further supported by the fact that there are scores as low as the strongly disagree and disagree options, which is 1 and 2 on the Likert scale used. These have been observed for job satisfaction $(n=49)$ and work engagement $(n=8)$. Through social interaction, employees can influence each other's views (Schaufeli \& Bakker, 2004; Schaufeli \& Taris, 2014). Thus, swift intervention is necessary to limit the possibility of the lesser satisfied and engaged employees influencing those with more positive views.

\section{Acknowledgements Competing interests}

The authors declare that they have no financial or personal relationships that may have inappropriately influenced them in writing this article.

\section{Author's contributions}

R.L.T. conducted the research and wrote the article. V.N. and T.H.H.H. supervised the research and co-wrote the article.

\section{Ethical considerations}

This article followed all ethical standards for a research without direct contact with human or animal subjects.

\section{Funding information}

This research received no specific grant from any funding agency in the public, commercial, or not-for-profit sectors.

\section{Data availability}

Data can be shared anytime for the purpose of this publication's processes and is available on request from the corresponding author R.L.T.

\section{Disclaimer}

The views expressed in this article are those of the authors' own and not an official position of any particular institution or funder.

\section{References}

Abu-Shamaa, R., Al-Rabayah, W.A., \& Khasawneh, R.T. (2015). The effect of job satisfaction and work engagement on organizational commitment. The IUP Journal of Organizational Behavior, 14(4), 1-27.

Allwood, C.M. (2012). The distinction between qualitative and quantitative research methods is problematic. Quality and Quantity: International Journal of Methodology, 46(5), 1417-1429.

Alzyoud, A.A.A. (2018). Job satisfaction and work engagement moderated by trust. International Journal of Economics, Commerce and Management, 6(11), 125-139.

Ani, M., \& Mirela, F. (2016). Exploring the job satisfaction of public and private employees. Proceedings of the 10th International Conference on Business Administration, 13-15 February (pp. 138-144). Barcelona: Social Science Research Network.

Arifin, Z., Nirwanto, N., \& Manan, A. (2019). Improving the effect of work satisfaction on job performance through employee engagement. International Journal of Multi Discipline Science, 2(1), 1-9.

Auditor-General of South Africa. (2017). Auditor-general reports a slow but noticeable four-year improvement in national and provincial government audit results. Pretoria: Auditor-general of South Africa.

Auditor-General of South Africa. (n.d.). The role of the Auditor-general. Retrieved from http://www.agsa.co.za/Portals/0/Audit101/The_role_of_the_Auditor-General.pdf.

Aziri, Z. (2011). Job satisfaction: A literature review. Management Research and Practice, 3(4), 77-86.

Bakker, A.B. (2017). Strategic and proactive approaches to work engagement. Organisational Dynamics, 46, 67-75.

Bakotić, D. (2016). Relationship between job satisfaction and organisational performance. Economic Research-Ekonomska Istraživanja, 29(1), 118-130.

Batura, N., Skordis-Worrall, J., Thapa, R., Basnyat, R., \& Morrison, J. (2016). Is the Job Satisfaction Survey a good tool to measure job satisfaction amongst health workers in Nepal? Results of a validation analysis, BMC Health Services Research, 16(308), 1-13.

Bellani, E., Ramadhani, S., \& Tamar, M. (2018). Job satisfaction as predictor of employee engagement. Proceedings of 8th International Conference of Asian Association of Indigenous and Cultural Psychology, Indonesia, 21-23 August (pp. 15-19). Paris: Atlantis Press. 
Bhorat, A., Naidoo, K., \& Yu, D. (2014). Trade unions in an emerging economy: The case of South Africa. WIDER Working Paper 2014/055. Tokyo: United Nations University.

Bucăţa, G., \& Rizescu, A.M. (2017). The role of communication in enhancing work effectiveness in an organization. Land Forces Academy Review, 23(85), 49-57.

Department of National Treasury. (2011). Local government budgets and expenditure review: 2007/07 - 2012/13. Pretoria: Government Printer.

Department of National Treasury. (2015). Strategic plan 2015 to 2019. Pretoria: Government Printer.

Department of National Treasury. (2019). Annual performance plan. Pretoria: Government Printer.

Department of National Treasury. (2020). 2020 budget review. Pretoria: Government Printer.

Dhakal, C. (2018). Interpreting the Basic Outputs (SPSS) of Multiple Linear Regression. International Journal of Science and Research, 7, 1448-1452.

Do Monte, P. (2017). Public versus private sector: Do workers' behave differently? EconomiA, 18(2017), 229-243.

Field, J. (2008). Job Satisfaction model for retention. Retrieved from http:// talentedapps.wordpress.com/2008/04/11/job-satisfaction-model-for-retention

Gable, S.L., \& Haidt, J. (2005). What (and why) is positive psychology? Review of General Psychology, 9(2), 103-110.

Garg, K., Dar, I.A., \& Mishra, M. (2017). Job satisfaction and work engagement: A study using private sector bank managers. Advances in Developing Human Resources, 20(1), 1-14.

Gilbreth, F.B. (1911). Motion study: A method for increasing the efficiency of the workman. New York: Sturgis and Walton.

Gogtay, N.J., \& Thatte, U.M. (2017). Principles of correlation analysis. Journal of the Association of Physicians of India, 65, 78-81.

Inuwa, M. (2016). Job satisfaction and employee performance: An empirical approach. The Millennium University Journal, 1(1), 90-103.

Jacobs, S., Renard, M., \& Snelgar, R. (2014). Intrinsic rewards and work engagement in the South African retail industry, South Africa Journal of Industrial Psychology, 40(2), 1-13.

Joshi, A., Kale, S., Chandel, S., \& Pal, D.K. (2015). Likert scale: Explored and explained. British Journal of Applied Science and Technology, 7(4), 396-403.

Khan, A., Khan, S., Nawaz, A., \& Qureshi, Q.A. (2013). Theories of job-satisfaction: Global applications \& limitations. Gomal University Journal of Research, 26(2) $45-62$.

Khan, A., \& Khandaker, S. (2016). Public and private organisation: How different or similar are they? Journal of Siberian Federal University. Humanities \& Socia Sciences, 12(2016), 2873-2885.

Khan, A.H., Nawaz, M.M., Aleem, M., \& Hamed, W. (2012). Impact of job satisfaction on employee performance: An empirical study of autonomous medical institution of Pakistan. African Journal of Business Management, 6(7), 2697-2705.

Kim, W., Kolb, J.A., \& Kim, T. (2012). The relationship between work engagement and performance: A review of empirical literature and a proposed research agenda. Human Resource Development Review, 12(3), 248-276.

Kulikowski, K. (2019). Measurement of work engagement with single-item measure. Polish Psychological Bulletin, 49(4), 406-415.

Lambert, L., Pasha-Zaidi, N., Passmore, H.-A., \& York Al-Karam, C. (2015). Developing an indigenous positive psychology in the United Arab Emirates. Middle Eas Journal of Positive Psychology, 1(1), 1-23.

Latif, M.M., Ahmad, S., Qasim, M., Mushtaq, M., Ferdoos, A., \& Naeem, H. (2013) Impact of employee's job satisfaction on organizational performance. European Journal of Business and Management, 5(5), 166-171.

Lopez, S.J., \& Gallagher, M.W. (2009). A case for positive psychology. In J. Lopez \& C.R. Snyder (Eds.), The Oxford handbook of positive psychology (pp. 3-6). Oxford: Oxford University Press.

Ludviga, I., \& Kalvina, A. (2016). Exploring the relationships between job satisfaction, work engagement and loyalty of academic staff. International Journal of Social, work engagement and loyalty of academic staff. International Journal of Social, Behavioural 995.

Macleod, D., \& Clarke, N. (2009). Engaging for success: Enhancing performance through employee engagement. A report to the government of the United Kingdom. Richmond: Office of the Public Sector Information.

Maleka, M., Paul-Dachapalli, L., Ragadu, S., Schultz, C., \& Van Hoek, L, (2020), Performance management, vigour, and training and development as predictors of job satisfaction in low-income workers, South African Journal of Human Resources Management, 18(2020), 1-10.

Manikandan, S. (2011). Frequency distribution. Journal of Pharmacology and Pharmacotherapeutics, 2(1), 54-56.

Mills, M., Fleck, C., \& Kozikowski, A. (2013). Positive psychology at work: A conceptual review, state-of-practice assessment, and a look ahead. The Journal of Positive Psychology, 8(2), 153-164.

Mogab, J., Kishan, R., \& Vacaflores, D.E. (2013). Labour market rigidity and foreign direct investment: The case of Europe. Applied Econometrics and International Development, 13(1), 35-54.

Musenze, T., \& Mayende, T. (2020). A psychometric evaluation of A the 17-itemed Utrecht work engagement scale in Uganda, African Journal of Psychological Assessment, 2(0), 1-9.
Orin, C.D. (2010). Why the workplace needs positive psychology. Retrieved from http://qllab.org/Publications/PosPsychWorkingPaper_OrinDavis.pdf

Pallant, J. (2007). SPSS survival manual: A step by step guide to data analysis using SPSS for Windows. Maidenhead: Open University Press.

Parliament of South Africa. (2016). How the budget works for us. Pretoria: Government Printer.

Popović, B., Maletić, R., \& Paunović, T. (2015). Employee satisfaction survey in function of business improvement. Journal of Sustainable Business and Management Solution in Emerging Economies, 20(76), 31-40.

Rabbanee, F., Yasmin, S., \& Mamun, A. (2016). Determinants of job satisfaction: A study on Bangladesh perspective International Research of Commerce and Behavioural Science, 1(8), 28-34.

Rana, S., Pant, D., \& Chopra, P. (2019). Work engagement and individual work performance: Research findings and an agenda for employee relationships. Journal of Emerging Technologies and Innovative Research, 6(5), 17-32.

Republic of South Africa. (1995). Labour Relations Act, No 33 of 1995. Pretoria: Government Printers.

Republic of South Africa. (1999). Public Finance Management Act, No 1 of 1999. Pretoria: Government Printers.

Saks, A.M. (2006). Antecedents and consequences of employee engagement. Journa of Managerial Psychology, 21(7), 600-619.

Saunders, M., Lewis, P., \& Thornhill, A. (2016). Research methods for business students. Harlow: Pearson Education Ltd.

Schaufeli, W.B. (2012). Work engagement. What do we know and where do we go? Romanian Journal of Applied Psychology, 14(1), 3-10.

Schaufeli, W.B. (2013). What is engagement? In: C. Truss, K. Alfes, A. Delbridge, A Shantz, \& E. Soane, (Eds.), Employee engagement in theory and practice (pp. 1536). London: Routledge.

Schaufeli, W.B., \& Bakker, A. (2004). Utrecht Work Engagement Scale. Domplein Utrecht University.

Schaufeli, W.B., \& Taris, T.W. (2014). A critical review of the job demands-resources model: Implications for improving work and health. In: G.G. Bauer \& O. Hamming (Eds.), Bridging occupational, organizational and public health: A transdisciplinary (Eds.), Bridging occupational, organization
approach (pp. 1-11). Dordrecht: Springer.

Seligman, M.E.P. (1994). What you can change \& what you can't. New York, NY: Knopf.

Seligman, M.E.P., \& Csikszentmihalyi, M. (2000). Positive psychology: An introduction. American Psychologist, 55(1), 5-14.

Skaalsvik, H. (2017). Service branding: Suggesting and discussing four perspectives influencing a value-creating service brand at the company level. Retrieved from https://www.intechopen.com/books/advancing-insights-on-brand-management/ service-branding-suggesting-and-discussing-four-perspectives-influencing-avalue-creating-service-br

Spector, P.E. (1985). Measurement of human service staff satisfaction: Development of the Job Satisfaction Survey. American Journal of Community Psychology, 13(6), 693-713.

Syeda, B., Nighat, P., \& Syeda, B. (2017). Emotional intelligence and job commitment: Meditational role of job satisfaction and job performance. Pakistan Business Review, 18(4), 904-923.

Steyn, R. (2016). Sex differences and work engagement: A study across 27 South African companies. Journal of Contemporary Management, 13, 461-481.

Taherdoost, H. (2016). Validity and reliability of the research instrument; how to test the validation of a questionnaire/survey in a research. International Journal of Academic Research in Management, 5(3), 28-36.

Taylor, F.W. (1919). The principles of scientific management. New York, NY: Harper and Brothers Publishers.

Tepayakul, R., \& Rinthaisong, I. (2018). Job satisfaction and employee engagement among human resources staff of Thai private higher education institutions. The Journal of Behavioral Science, 13(2), 68-81.

Uysal, H.T., Aydemir, S., \& Genc, E. (2017). Maslow's hierarchy of needs in 21st century: The examination of vocational differences. In: A. Hasan, A. Elliott, \& R Turgeon (Eds.), Researches on science and art in 21st century Turkey (2nd ed., pp. 211-227). Ankara: Gece Kitapligi.

Viswesvaran, C., Schmidt, F.L., \& Ones, D.S. (2005). Is there a general factor in ratings of job performance? A meta-analytic framework for disentangling substantive and error influences. Journal of Applied Psychology, 90(1), 108-131.

Wickramasinghe, N., Dissanayake, D., \& Abeywardena, G. (2018). Validity and reliability of the Utrecht work engagement scale-student version in Sri Lanka, BMC Res Notes, 17(277), 1-6.

Wright, T.A. (2006). The emergence of job satisfaction in organisational behaviour. Journal Management History, 12(3), 262-277.

Yalabik, Z.Y., Rayton, B.A., \& Rapti, A. (2016). Facets of job satisfaction and work engagement. Evidence-Based Human Resource Management, 5(3), 248-265.

Yongxing, G., Hongfei, D., Baoguo, X., \& Lei, M. (2017). Work engagement and job performance: The moderating role of perceived organizational support. Anales De Psicología, 33(3), 708-713.

Ziapour, A., \& Kianipour, N. (2015). A study of the relationship between characteristic traits and employee engagement (a case study of nurses across Kermanshah, Iran in 2015). Journal of Medicine and Life, 8(3), 134-140.

Zuñiga-Collazos, A., Castillo-Palacio, M., \& Padilla-Delgado, L. (2019). Organizationa competitiveness: The conceptualization and its evolution. Journal of Tourism and Hospitality Management, 7(1), 195-211. 